\title{
Selective fluorescence labeling: time-lapse enzyme visualization during sugarcane hydrolysis
}

\author{
Makiko Imai ${ }^{1}$, Asako Mihashi², Tomoya Imai', Satoshi Kimura ${ }^{1,3}$, Tomohiko Matsuzawa ${ }^{4}$, Katsuro Yaoi ${ }^{4}$, \\ Nozomu Shibata ${ }^{5}$, Hiroshi Kakeshita ${ }^{5}$, Kazuaki Igarashi ${ }^{5}$, Yoshinori Kobayashi ${ }^{2}$ and Junji Sugiyama ${ }^{1,6^{*}}$ (1)
}

\begin{abstract}
Enzymatic biomass saccharification is an important process for bioethanol production. Hitherto, numerous cellulase cocktails (crude enzyme) have been developed to improve enzymatic activity. For this purpose, the synergy of incorporating hydrolase functionality within a cellulase cocktail is a key function. However, such synergistic action, by potentially numerous different enzyme types, on biomass tissue has not been considered despite the importance toward the realistic case of biomass saccharification. This study aims to visualize the behavior of each of the key cellulase components on biomass tissue during saccharification. Time-lapse fluorescence microscopy observations were conducted during saccharification of a thin transverse sugarcane section to monitor enzymes modified with a fluorescence dye. Statistical image analysis successfully demonstrated a unique adsorption/desorption behavior of each enzyme component. Particularly, the behavior of endoxylanase10 (Xyn10), which was recently discovered from Penicillium sp. as a high-performance xylanase, displayed remarkable adsorption on tissues of sugarcane, which accounts for the superior activity of the cellulase mixture with Xyn10.
\end{abstract}

Keywords: Cellulose, Xylanase, Sugarcane tissue, Fluorescence microscopy, Statistical image analysis

\section{Introduction}

Development of new alternative sources of energy is a global hot topic, and recently a wealth of interdependent research has focused on the use of inedible biomass such as lignocellulose. Among the numerous biomass materials, sugarcane has received significant attention at the industrial scale as one of the lignocelluloses for bioethanol production, particularly, with bagasse (fiber remaining after extracting sugarcane juice) being a focus of attention.

As a first step to produce bioethanol from lignocellulose, it is necessary to hydrolyze cellulose and hemicellulose polymers into their respective monomers. Investigations have recently focused on enzymatic hydrolysis as the method of hydrolysis because of the

\footnotetext{
${ }^{*}$ Correspondence: sugiyama.junji.6m@kyoto-u.ac.jp

${ }^{1}$ Research Institute for Sustainable Humanosphere, Kyoto University,

Gokasho, Uji, Kyoto 611-0011, Japan

Full list of author information is available at the end of the article
}

positive environmental assessment received, despite several problems in this process. For example, the yield of saccharification reaches the limit by low concentrations of cellulase cocktail [1]. The mechanism of this phenomenon still requires elucidation; however, studies have suggested a complicated process of nonproductive and nonspecific adsorption to substrates [2, 3], deactivation of enzymes [4], product inhibition [5], etc. To circumvent the limitation in hydrolysis activity, large amounts of enzymes are required. Furthermore, the enzyme cost is another factor to consider when commercializing [6, 7]. Therefore, there is a demand to develop new strategies that allow efficient hydrolysis using minimum amounts of enzymes.

The native crude cellulase is composed of multiple enzyme components, each of which offers individual function and specific activity. The three main components are cellobiohydrolase (CBH), endoglucanase (EG), and $\beta$-glucosidase (BGL). Numerous reports have 
detailed the synergistic effect among these components [8-10]. Enzyme-substrate specificity has received significant attention that includes the development of visually observing their interactions. Classically, gold-labeled individual enzymes were visualized by electron microscopy $[11,12]$, and thereafter, cellulose-binding modules (CBMs) with fluorescein isothiocyanate [13, 14] were observed. A single molecular motion of a green fluorescence protein-tagged CBM on a cellulose crystal of Valonia ventricosa was analyzed [15]. Furthermore, a fluorescence resonance energy-transfer technique [16] demonstrated that cellulases were located only a few $\mathrm{nm}$ from each other on the surface of a cellulose microfibril. More impressively, by high-speed atomic force microscopy, the running motion of CBH I particles, on a cellulose microfibril, from the cell wall of Cladophora sp. was directly visualized [17]. The authors further investigated, and observed a type of "traffic jam" on the cellulose surface, and by theoretical analysis, elucidated a possible mechanism of the enzyme-substrate interaction [18].

As described above, the observation of 'individual' cellulase components has been successfully reported. Hitherto, however, such observations have not been directed toward the visualization of each enzyme component in cellulase mixture working synergistically with real biomass tissue. Therefore, the focus of this study was to visualize the pattern of adsorption and desorption of each enzyme component acting on a section of sugarcane by using fluorescence microscopy combined with a newly developed image analysis technique.

Furthermore, this study also focused on xylanases as important enzymes for the hydrolysis of biomass. Two xylanases were selected for the visualization experiment: endoxylanase III (Xyn III) from Trichoderma reesei, well known to be efficient; and endoxylanase10 (Xyn10) from Penicillium sp., a recently found high-performance enzyme.

\section{Materials and methods}

\section{Enzyme preparation}

The enzymes used in this study were CBH I (TrCel7A), CBH II (TrCel6A), EG I (TrCel7B), EG II (TrCel5A), EG IV (TrCel61A), Xyn III, $\beta$-xylosidase (TrXyl3A, BXL), BGL I, and Xyn10 (PspXyn10). CBH I, CBH II, EG I, EG II, EG IV, Xyn III and BXL were derived from the $T$. reesei strain PC-3-7 [19] and BGL I was derived from Aspergillus aculeatus [20]. These eight enzymes were heterologously expressed in A. oryzae (Ozeki Co. Ltd., Hyogo, Japan) following the method reported by Kawai et al. [21]. Each enzyme was purified from the culture supernatant of $A$. oryzae cells by hydrophobic chromatography (TOYOPEARL ${ }^{\circledR}$ Butyl-650) followed by anion exchange chromatography (TOYOPEARL ${ }^{\circledR}$ DEAE-650).
To prepare Xyn10 from Penicillium sp., the pspxyn10 gene was amplified from pUC-Pcbh1-pspxyn10-amdS plasmid [22] by a polymerase chain reaction and expressed in A. oryzae cells under the control of an improved enoA promoter (PenoA142f) [23] that harbored 12 tandem repeats of the cis-acting element (region III) of the agdA promoter [24]. A. oryzae cells expressing the pspxyn 10 gene were cultured in a DP medium (2\% dextrin hydrate, $1 \%$ peptone) containing $0.5 \%$ potassium dihydrogen phosphate, $0.05 \%$ magnesium sulfate, $0.187 \%$ L-glutamic acid monosodium salt, and $0.003 \%$ L-methionine at $30{ }^{\circ} \mathrm{C}, 105 \mathrm{rpm}$ for 3 days. After cultivation, the A. oryzae cells were removed by filtration $(0.45 \mu \mathrm{m})$ and Xyn10 was purified as described above.

\section{Enzyme labeling with a fluorescent dye}

Herein, CBH I, CBH II, EG I, EG II, Xyn III, and Xyn10 were labeled with a fluorescent dye as theses enzymes are the main components of a wild-type cellulase and have important functions.

Each enzyme was labeled with Alexa Fluor ${ }^{\circledR} 546$ NHS Ester (Invitrogen, California, USA) in accordance with an attached instruction. The fluorescent molecule forms a covalent bond with a primary amine group in enzyme. Determination of the protein concentration was performed using a Quick Start ${ }^{\mathrm{TM}}$ Bradford protein assay (BioRad, California, USA), and a gamma-globulin standard was used throughout this study. Bio-Gel ${ }^{\circledR}$ P-4Gel fine (Bio-Rad, wet bead size 45-90 $\mu \mathrm{m}$, molecular weight exclusion limit of $>4000$ ) was used to separate the labeled enzyme from the free dye. The absorbance at $554 \mathrm{~nm}$ of the labeled enzyme solution was measured to calculate the degree of labeling (DL), using the following formula:

$$
\mathrm{DL}=\left(A_{554} \times k\right) /\left(\mu_{\text {ext }} \times C_{\text {protein }}\right),
$$

where DL is the amount of moles of dye per mole of protein, $A_{554}$ is the absorbance at $554 \mathrm{~nm}, k$ is a dilution factor, $\mu_{\text {ext }}$ is the molar extinction coefficient of Alexa Fluor ${ }^{\circledR} 546$ NHS Ester at $554 \mathrm{~nm}\left(104,000 \mathrm{~cm}^{-1} \mathrm{M}^{-1}\right)$, and $C_{\text {protein }}$ is the protein concentration $(\mathrm{M})$.

\section{Assessment of labeled xylanases}

To compare the enzymatic activity of two xylanases, a saccharification test was investigated in the presence of cellulase mixture including Xyn III or Xyn10. The substrate, sugarcane (Saccharum officinarum) bagasse powder, was sieved through a 1-mm mesh and pretreated by autoclaving in $1 \%$ sodium hydroxide solution at $120{ }^{\circ} \mathrm{C}$ for $20 \mathrm{~min}$. The composition was estimated as: cellulose (63\%), hemicellulose (18\%), lignin (7.6\%), and ash (4.0\%). The bagasse (10 $\mathrm{mg}$ on a dry matter basis) was hydrolyzed in $0.1 \mathrm{M}$ acetate buffer $\left(\mathrm{pH} 5.0\right.$ ) at $50{ }^{\circ} \mathrm{C}$, shaking at $150 \mathrm{rpm}$. The total solution volume was $1 \mathrm{~mL}$ and 
the enzyme concentration was $3 \mathrm{mg} / \mathrm{g}$ of substrate. The enzyme composition is the same as that described later in the microscopy section. The experiments were performed for both nonlabeled and labeled xylanases. The supernatant was collected at $5,24,48$, and $96 \mathrm{~h}$ to measure D-glucose yield using a CII Test Wako kit (Wako, Osaka, Japan), and D-xylose yield using a D-xylose kit (Megazyme, Wicklow, Ireland).

\section{Fluorescence microscopy of a selectively labeled enzyme in a cellulase cocktail}

Transverse sections (30- $\mu$ m-thick) were cut from a stem of sugarcane harvested in Okinawa, Japan, by a microtome equipped with a freezing stage. The sections were treated in $0.5 \%$ sodium hydroxide using an oil bath at $100{ }^{\circ} \mathrm{C}$ for $1 \mathrm{~h}$. After washing thoroughly, the treated sections were used as the substrate. The enzyme mixture comprised purified components of CBH I $35 \mathrm{wt} \%$, CBH II 20 wt\%, EG I 15 wt\%, EG II 5 wt\%, EG IV 5 wt\%, BGL I 5 $w t \%$, BXL 5 wt\%, and Xyn III $10 w t \%$. One of the enzymes was replaced with a fluorescent-labeled enzyme at a fixed ratio of $5 \mathrm{wt} \%$ (total enzyme basis); for example, a system comprising labeled $\mathrm{CBH}$ I at $5 \mathrm{wt} \%$ and nonlabeled $\mathrm{CBH}$ I at $30 \mathrm{wt} \%$. For comparison purpose, Xyn III was replaced with Xyn10 to visualize the functional difference between the two xylanases.

A pretreated section was mounted on a glass slide together with a $25-\mu \mathrm{L}$ aliquot of an enzyme mixture ( $\sim 40 \mathrm{mg} / \mathrm{g}$ biomass). A cover slip was then placed on top of the specimen and sealed with nail polish to prevent water evaporating during the reaction. The preparation was performed on a thermostage, maintained at $50{ }^{\circ} \mathrm{C}$, with an inverted fluorescent microscope (IX71, Olympus, Tokyo, Japan) under a constant illumination flux from a super-high pressure mercury lamp and a $4 \times$ objective lens (UPlanFLN, NA: 0.13, Olympus). Images $(1600 \times 1200$ pixels, 8 bit RGB) were recorded every $5 \mathrm{~min}$ for $360 \mathrm{~min}$ in fluorescent mode with a charge-coupled device camera having an exposure time set at $500 \mathrm{~ms}$ (DP 73, Olympus). As the filter set, TRIRC-B (Semrock, N.Y., USA) was used comprising a bandpass excitation filter $(543 \mathrm{~nm} / 22 \mathrm{~nm})$, a dichroic mirror $(>562 \mathrm{~nm})$, and a bandpass emission filter $(593 \mathrm{~nm} / 40 \mathrm{~nm})$. No auto-fluorescence was detected in the presence of a nonfluorescent-labeled enzyme subjected to the same conditions.

\section{Relationship between the number of labeled enzymes and fluorescence image intensity}

Prior to image data interpretation, the relationship between the fluorescence intensity of the microscopic image and the labeled enzyme concentration was determined. A series of $2-\mu \mathrm{L}$ enzyme-labeled solutions, at various concentrations, were placed in a circle $(\phi=8 \mathrm{~mm})$ surrounded by water-resistant fluororesin on a glass slide, TF0808 (MATSUNAMI, Osaka, Japan). Thereafter, a cover slip was placed on the solution and observations made using fluorescent microscopy under the same conditions as previously described. The average fluorescence intensity was calculated from five different positions using ImageJ software, and plotted against the corresponding enzyme concentration.

\section{Time-lapse fluorescence profiles from two-dimensional images}

A stack of fluorescent images (at 5-min intervals) were carefully aligned by the registration algorithm proposed by Thévenaz et al. [25] as a plugin for ImageJ. A $500 \times 500$ pixel region was cropped, wherein one complete vascular bundle (VB) from the inner part of the stem was recorded. After conversion to a gray-scale, and noise reduction by median filtering, the intensity profiles from each pixel in an image stack were taken as a function of time. The 250,000 time-dependent intensity profiles were then classified into eight representative profiles by the $k$-Means algorithm, and the corresponding regions associated with the eight profiles were contour-mapped into two-dimensional images. The number of clusters was chosen to be slightly larger than the number of cell types in the region of interest: phloem, bundle sheath, metaxylem and parenchyma, which were expected to show different susceptibilities to the enzymatic attack. All calculations were performed in python 3.6 using the scikitlearn v0.19.2 [26] data mining tool.

\section{Results and discussion}

\section{Xylanase activity: effect of labeling}

As xylanase is known to be a key enzyme for the saccharification of biomass, the investigation herein studied two endo- $\beta$-xylanases, Xyn III and Xyn10, both of which belong to the glycoside hydrolase family $\mathrm{GH}-10$ in the CAZy database. Xyn III was observed by Xu et al. [27] to be a highly active xylanase enzyme, while Xyn10, developed by Kao Corporation, Tokyo, Japan [22], exhibits an even higher activity. Xyn III has no carbohydrate-binding module (CBM) and shows a high affinity to soluble xylan [28], while Xyn10 is an endo-type xylanase with a CBM 1 that demonstrates a high affinity to the surface of crystalline cellulose [22].

As previously reported [22], Xyn10 demonstrated a higher activity than Xyn III against alkali-pretreated sugarcane bagasse powder (Fig. 1), reconfirming the excellent performance of Xyn10.

Furthermore, a remarkable finding in this study for Xyn10 is that the production of xylose precedes that of 


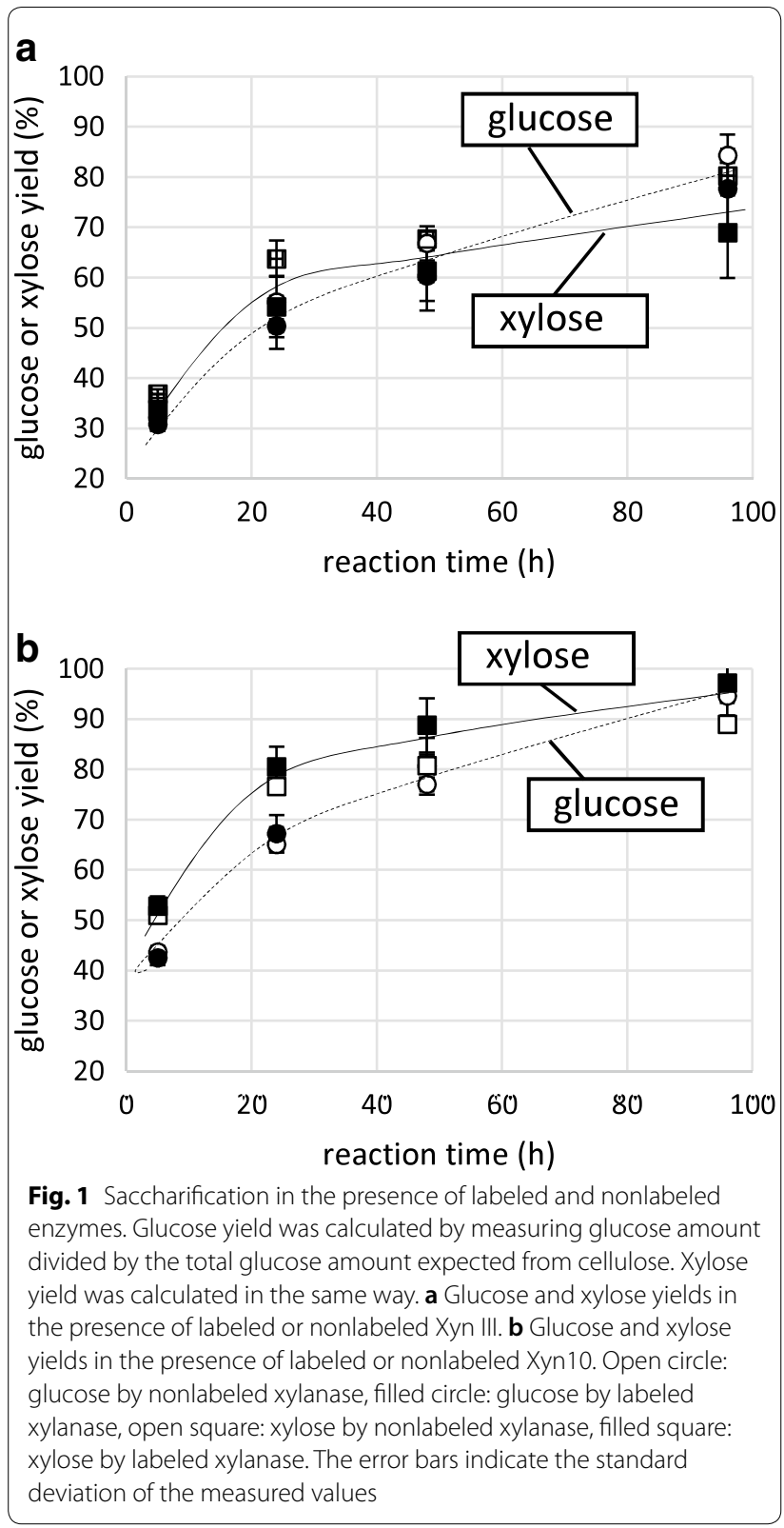

glucose, until $48 \mathrm{~h}$ of treatment (Fig. 1b). As part of the xylan structure is tightly bound to cellulose fibrils [29], effective xylanases may remove xylan from the surface of cellulose, which subsequently allows cellulose to be accessible to cellulase. Finally, the reaction progress appears to be similar for fluorescent-labeled and nonlabeled enzyme systems (Fig. 1), indicating that the enzyme labeling does not influence xylanase hydrolysis performance. Additionally, there was no significant influence hydrolysis performance for the other enzymes analyzed in this study (data not shown). Hence, enzyme
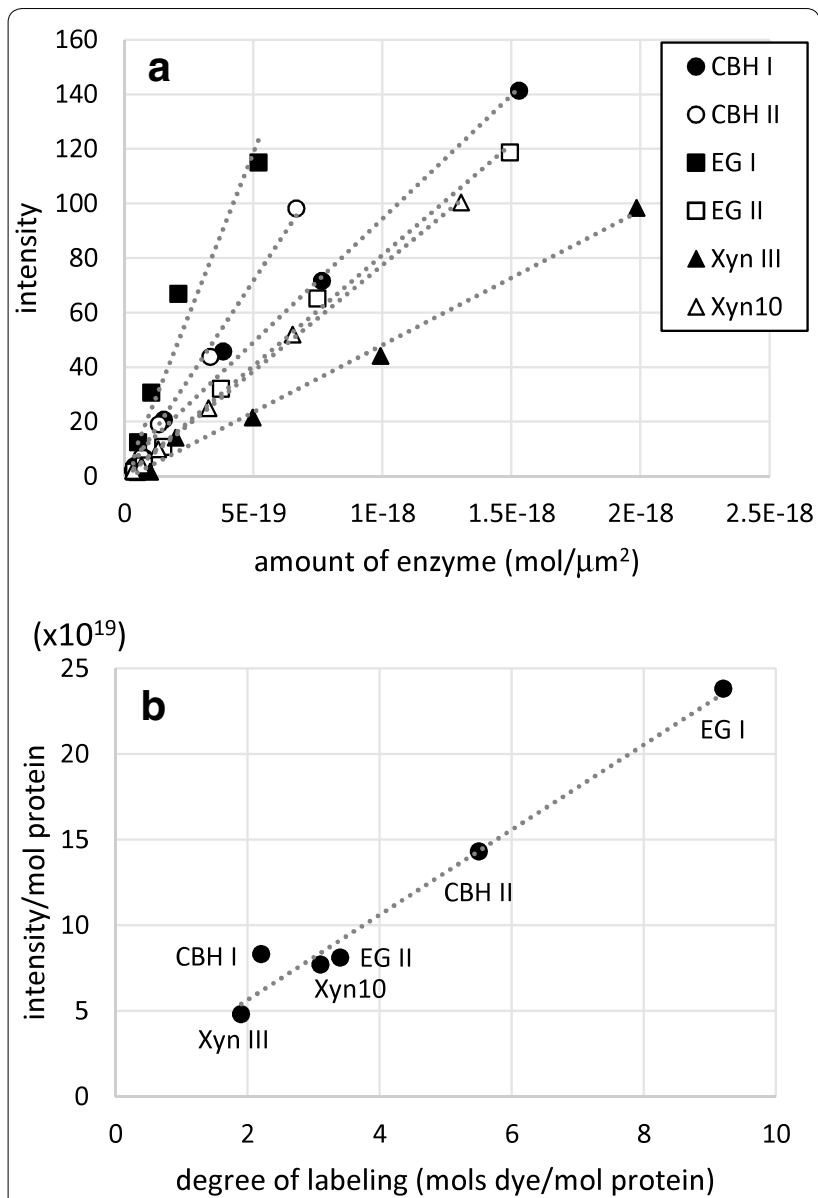

Fig. 2 a Relationship between image intensity and enzyme concentration. $\mathbf{b}$ Relationship between intensity per mole of protein and degree of labeling

labeling does not influence data interpretation derived from fluorescence microscopy in this study.

\section{Relationship between the number of labeled enzymes and fluorescence image intensity}

Fluorescence intensity of the labeled enzyme solution at various concentrations is plotted in Fig. 2a. Excellent linearity between the fluorescence microscopy intensities and the applied dose of individual enzymes was demonstrated. The intensity per mole of protein (the slope of each line), was calculated in Fig. 2a. When the slope was plotted against the degree of enzyme labeling for each enzyme (Fig. 2b), a linear relationship was also observed, indicating that fluorescence intensity is proportional to the number of fluorescence dye molecules regardless of the enzyme tagged. Therefore, the fluorescence intensity of each enzyme can be quantitatively compared by normalizing to $D L$ of the corresponding enzyme. 


\section{Changes to morphology and enzyme adsorption during hydrolysis}

The typical appearance of the VB of sugarcane during hydrolysis is presented in Fig. 3. The images were taken in both normal brightfield mode (Fig. $3 a-c$ ) and fluorescence mode (Fig. 3d-f). As shown in the brightfield image (Fig. 3c), the parenchyma cell wall substances distant from the VB are more susceptible to hydrolysis, and the image contrast was almost lost after $360 \mathrm{~min}$ of treatment. The thick-walled bundle sheath of the VB remained but became notably thinner. Initial adsorption of $\mathrm{CBH}$ I occurred at the parenchyma cells distant from the VB (Fig. 3d) and became more concentrated toward the VB outer areas (Fig. 3e) after $100 \mathrm{~min}$, which is composed of smaller-sized parenchyma cells and thinner-walled VB fibers. Thereafter, CBH I was observed only at highly lignified areas such as the bundle sheath. As such, it was possible to visualize the substrate degradation pattern and the corresponding enzyme distribution.

\section{Time-lapse analysis of individual enzymes}

As a negative control, free Alexa Fluor ${ }^{\circledR} 546$ NHS Ester was tested under the same experimental conditions. No fluorescence of dyes on sugarcane sections was observed. A concept of the analysis is given in Fig. 4. A stack of images were carefully aligned, as shown in Fig. 4a. From a set of images, 250,000 intensity profiles were obtained, with some intensity profiles being shown in Fig. 4b. Several profile patterns are clearly observed; flat profiles (background), constant increasing or decreasing profiles, profiles with maximum peak, and so on. The typical center profiles obtained by the common method of vector quantization ( $k$-means clustering) are represented in Fig. 4c. The number of clusters was set at eight. Finally, all pixels were colored corresponding to the profiles (Fig. 4d). In this way, the adsorption/desorption behavior was analyzed in a $2 \mathrm{D}$ image for each labeled enzyme.

Figure 5 shows the intensity profiles of each enzyme together with the 2D distribution image. To compare intensity as a function of enzyme concentration, the intensity profiles were divided by $D L$. Thereafter, the labeled enzyme was fixed at $5 \mathrm{wt} \%$, based on the total number of enzymes present in the system. Therefore, the intensity was converted to the actual enzyme concentration; for example, the intensity was multiplied by seven in the case of $\mathrm{CBH}$ I. The patterns from $\mathrm{CBH}$ I, CBH II, EG I, EG II, and Xyn10, were somehow similar to one another, with a pattern displaying two types of
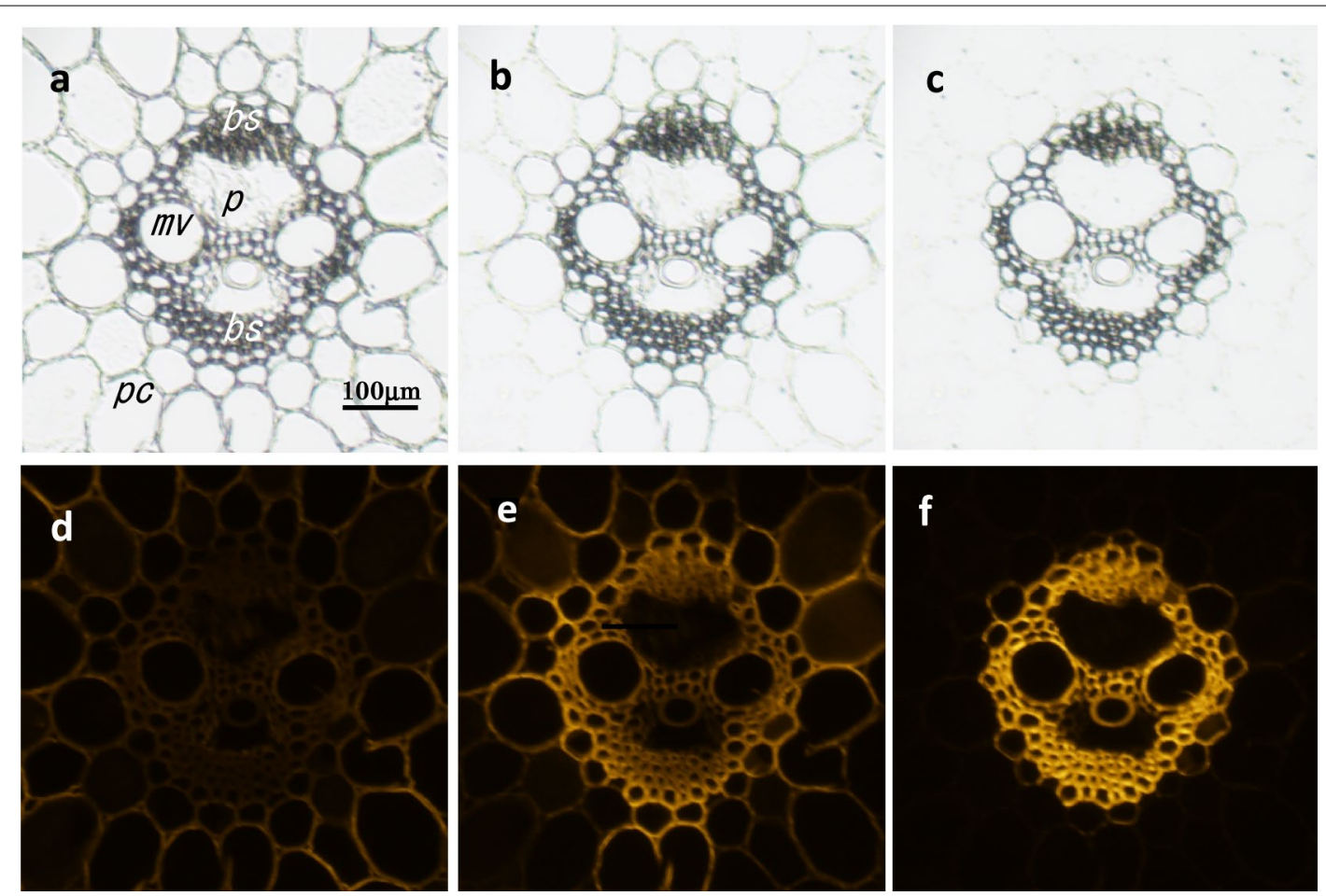

Fig. 3 Typical microscopy images during hydrolysis in the presence of mixed enzymes containing labeled cellobiohydrolase (CBH) I. Hydrolysis time: a, d 0 min, b 90 min, e 100 min, c, f 360 min; a-c brightfield microscopy images; $\mathbf{d}-\mathbf{f}$ fluorescent microscopy images. bs bundle shearth, $p$ phloem, $p c$ parenchyma, mv metaxylem vessel 
a

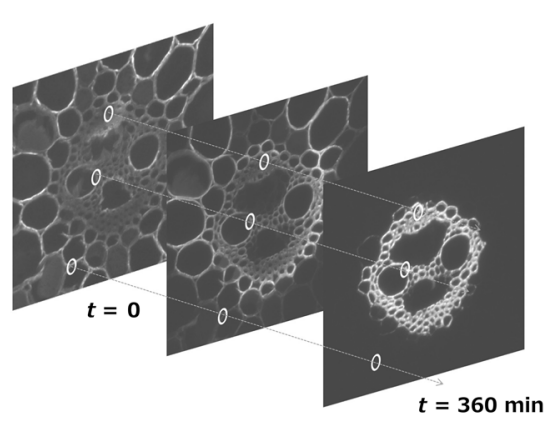

C

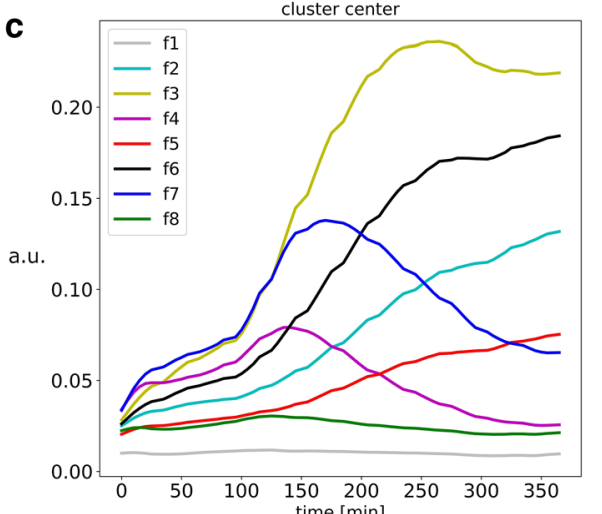

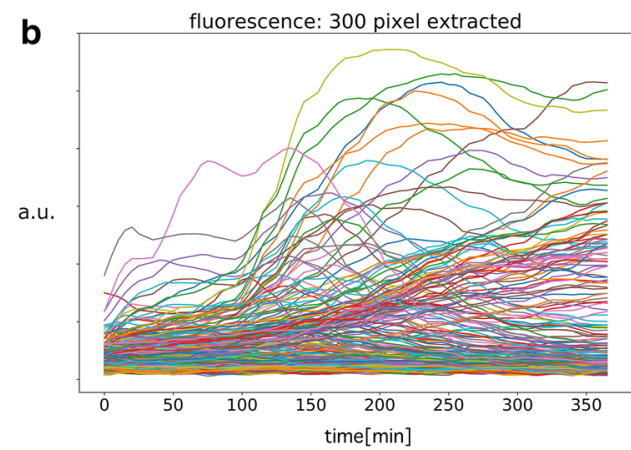

d

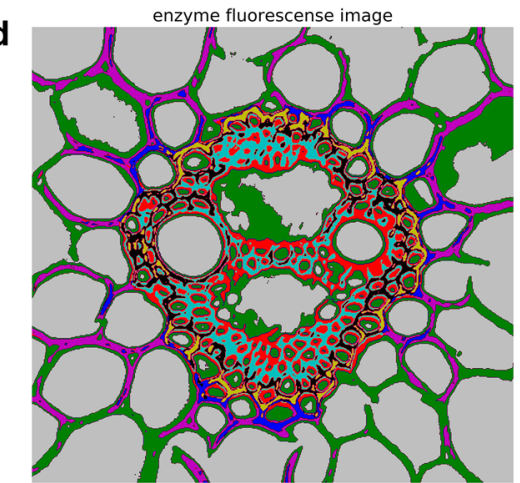

Fig. 4 A time-lapse flow-diagram observation of enzyme localization in a sugarcane section. A stack of image slices was registered and carefully aligned (a). Intensity at each pixel point in the stack as a function of time. Up to 300 profiles randomly extracted from 250,000 profiles in total were exemplified in $\mathbf{b}$. The eight representative profiles obtained by $k$-means clustering (c) together with a typical contour map of the corresponding eight regions $(\mathbf{d})$

profiles, one having a maximum peak and the other simply increasing as a function of time. The profile having maximum peak derives from the area of parenchyma cell walls of which are thin and contain little lignin, or parenchyma cells of a relatively small diameter, adjacent to the VB. The simply increasing profile derives from the area of bundle sheath cell walls of which are thick and contain significant amount of lignin, and is relatively enhanced at the outer VB area. Combining the profiles and the 2D enzyme distributions, it was concluded that all enzymes, except for Xyn III, were significantly adsorbed at the parenchyma cell walls distant from the VB during the initial stage of hydrolysis. The enzymes gradually moved toward smaller parenchyma cells adjacent to the VB. Thereafter, the enzymes desorbed from the hydrolyzed parenchyma and first re-adsorbed on areas exhibiting less lignin content before finally moving to areas of the VB cell walls containing the highest degree of lignin. Conversely, the behavior of Xyn III was significantly unique. Throughout the hydrolysis, the degree of Xyn III adsorption was relatively small, especially almost zero at the parenchyma cells (Fig. 5e), which demonstrates a remarkably different behavior from Xyn10, which also possesses a CBM similar to the other enzymes. The different behaviors between the two xylanases tested in this study are proposed to arise from the possession of CBMs. Xyn III of $T$. reesei was reported to be initially devoid of a CBM and Xyn III, expressed with a xylan-binding domain from Streptomyces olivaceoviridis E-86, showed higher adsorption toward insoluble xylan by a factor of two [28]. Furthermore, when Xyn10 that initially possessed a CBM [22] was modified to be devoid of a CBM, Xyn10 was no longer observed to adsorb onto the substrates (data not shown). Therefore, the CBM of xylanase was found to be critical for the interaction with xylan molecules that are closely associated with cellulose molecules at the substrate surface, which may improve the total activity of the cellulase system toward biomass. A time-lapse movie of the enzyme adsorption and desorption observed by fluorescence microscopy can be seen in the animation (Additional file 1: Online Resource S1). 

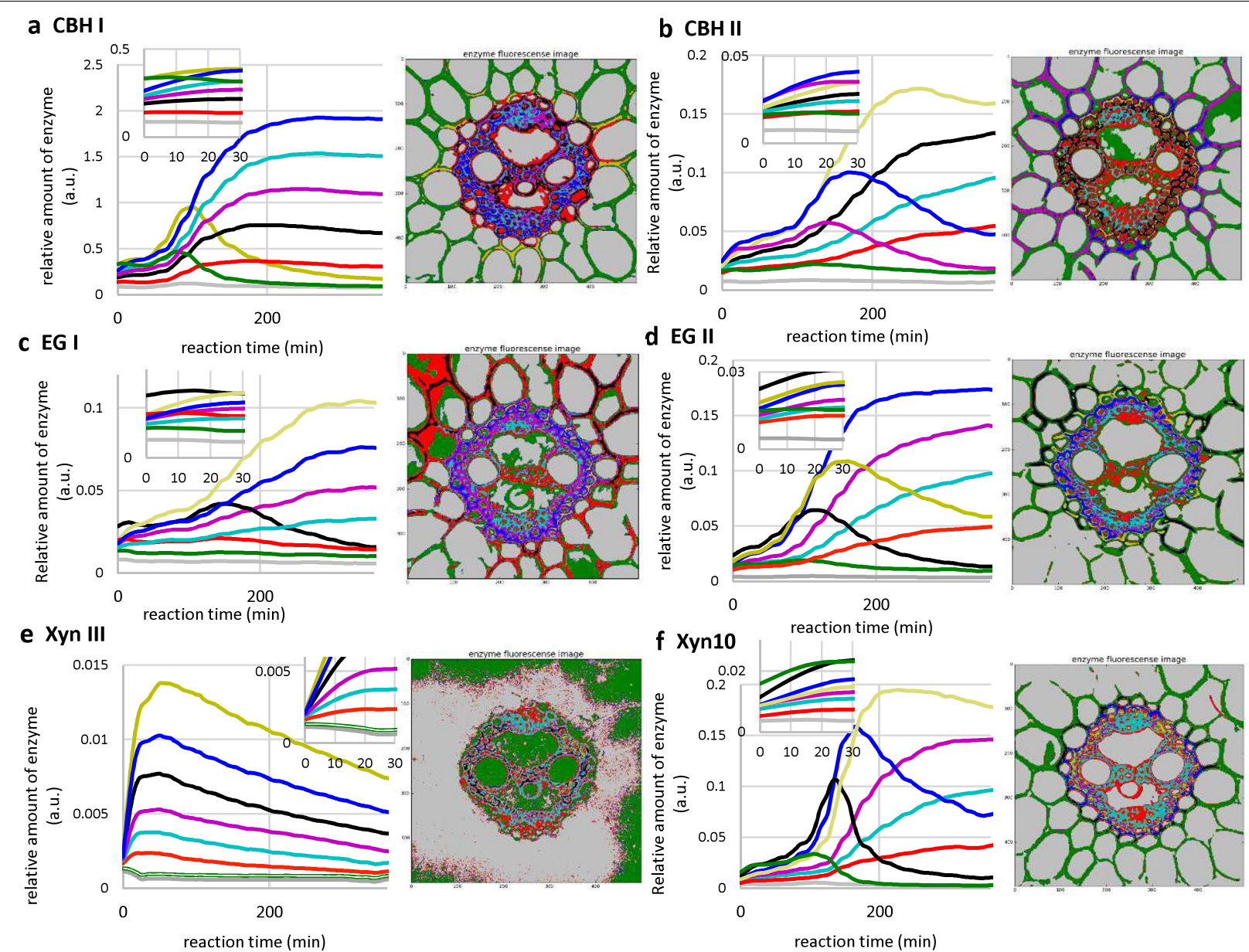

Fig. 5 Center adsorption/desorption profiles of each enzyme, together with the corresponding contour map in the 2D image. Inserts are enlarged profiles up to $30 \mathrm{~min}$

\section{Time-lapse analyses of enzyme activity in specific}

\section{anatomic areas}

Taking the maximum amount of adsorbed CBH I to be one, all the profiles shown in Fig. 5 were recalculated, and the relative amounts of each enzyme in the specific anatomic area were reproduced in Fig. 6. The specific anatomic areas are parenchyma cells, parenchyma cells near the VB, and the outermost cells of the VB.

As shown in Fig. 6, the major enzyme that adsorbed onto the surface of the substrate was unambiguously $\mathrm{CBH}$ I. Additionally, the profiles from CBH I, EG II, and Xyn10 were somehow similar in that these systems worked rapidly and moved to other regions that were more difficult to be hydrolyzed. Particularly, EG II and Xyn10 appeared to adsorb simultaneously; however, the desorption rate of Xyn10 was observed to proceed slightly quicker than EG II. Conversely, the degree of CBH II adsorption, which is known to work synergistically with $\mathrm{CBH}$ I $[9,30]$, was as low as oneseventh of $\mathrm{CBH}$ I, and furthermore, enzyme adsorption maxima occurred $\sim 1 \mathrm{~h}$ later than that of $\mathrm{CBH}$ I. This observation may explain partly why both these CBHs are considered to be processive enzymes; however, CBH II exhibits more of a less-processive nature as postulated earlier [31].

As for EG I and EG II, significant differences in the enzyme-substrate interactions are clearly demonstrated. As EG II was adsorbed to a significantly higher degree, it is suggested that EG II functions more efficiently near the cellulosic surface, while the adsorption of EG I to parenchyma was significantly hindered (Fig. 6a, b) and preferred molecules dissociated from the substrate surface. Additionally, pulp viscosity was reported to decrease to a greater extent in the presence of EG II when compared with EG I [32]. Furthermore, Horikawa et al. [33] reported that the difference in enzymatic activity 


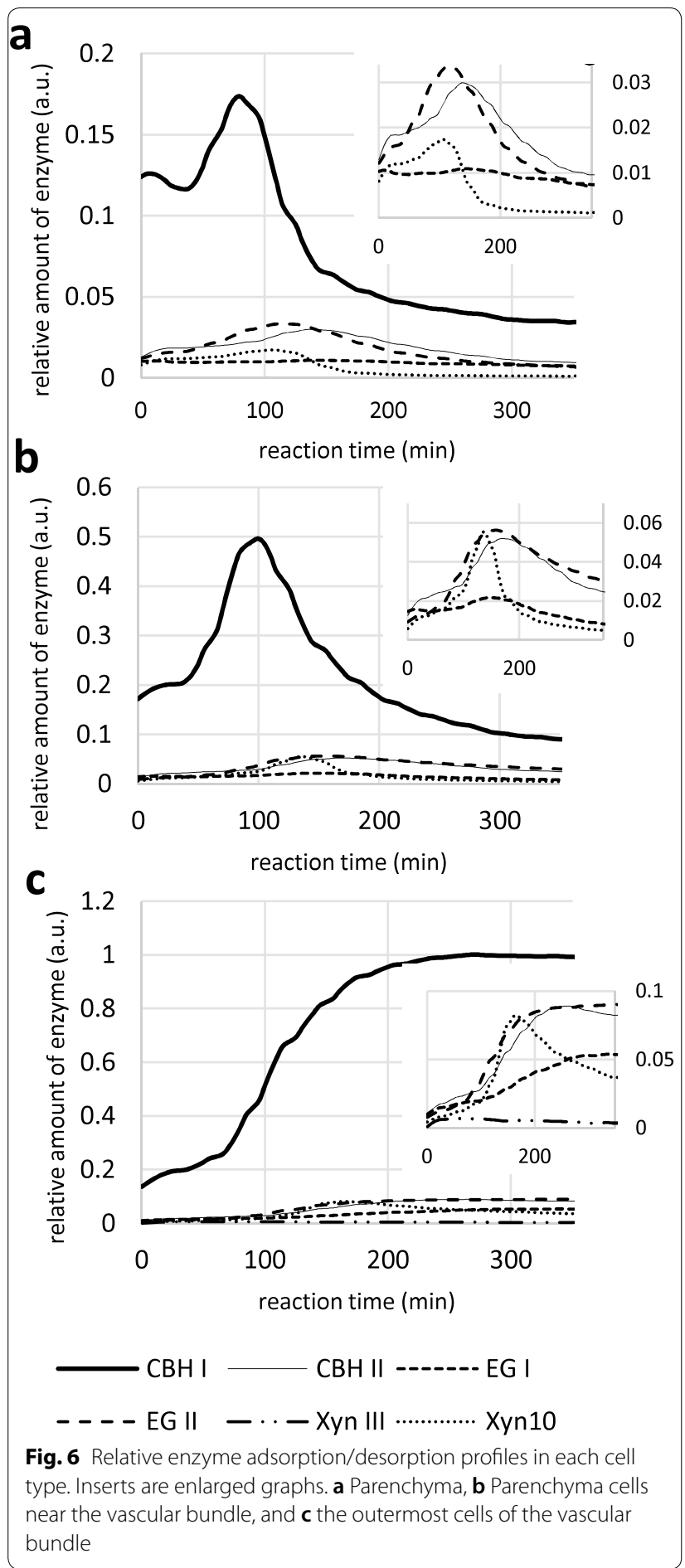

between EG I and EG II toward water-soluble carboxymethyl cellulose, was not distinguishable, whereas EG II significantly decreased the degree of polymerization of cellulose in a microfibrillar form than EG I. These reports agree well with our binding experiment.

\section{Conclusions}

From the time-lapse analyses of the transverse sections of sugarcane stems, it is clear that CBH I is the most important and indispensable enzyme, which adsorbed onto the substrate significantly more than any other enzyme, displaying a rapid adsorption/desorption action. Conversely, even though CBH II is a processive enzyme, similar to CBH I, the observed adsorption was less than expected. EG I and EG II display different modes of action toward the microstructure of the substrate: EG II directly attacks the surface, while EG I exhibits a preference toward disentangled molecules. As for xylanases, while Xyn10, in the presence of CBM, adsorbed at the initial stage of hydrolysis and desorbed soon after, the degree of Xyn III adsorption on any tissue of sugarcane was minimal. The visualization of individual enzymes is important to elucidate the orchestrated interactions between the enzyme and the complex biomass.

\section{Additional file}

Additional file 1: Online Resource S1. Time-lapse images during saccharification by fluorescence microscopy in the presence of labeled enzyme.

\section{Abbreviations}

CBH: cellobiohydrolase; EG: endoglucanase; BGL: $\beta$-glucosidase; Xyn: endoxylanase; BXL: $\beta$-xylosidase; DL: degree of labeling; VB: vascular bundle; CBM: carbohydrate-binding module.

\section{Authors' contributions}

$\mathrm{MI}, \mathrm{TI}$, and JS designed the study. MI observed bagasse sections and interpreted the action and interaction of enzymes, and was a major contributor in writing the manuscript. AM and YK pretreated bagasse powder and mixed enzyme components for saccharification. TI selected fluorescence dye and instructed a labeling method. SK set up the condition of fluorescence microscope for the time-lapse observation. TM, KY, NS, HK, and KI made and purified Xyn10. JS performed image analysis and contributed to writing the manuscript. All authors read and approved the final manuscript.

\section{Author details}

${ }^{1}$ Research Institute for Sustainable Humanosphere, Kyoto University, Gokasho, Uji, Kyoto 611-0011, Japan. ${ }^{2}$ Tsukuba Research Laboratory, Japan Bioindustry Association, Tsukuba, Ibaraki 305-8566, Japan. ${ }^{3}$ Graduate School of Agricultural and Life Science, The University of Tokyo, Bunkyo-ku, Tokyo 113-8657, Japan. ${ }^{4}$ Bioproduction Research Institute, National Institute of Advanced Industrial Science and Technology, Tsukuba Central 6, 1-1-1 Higashi, Ibaraki 305-8566, Japan. ${ }^{5}$ Biological Science Research, Kao Corporation, 1334 Minato, Wakayama, Wakayama 640-8580, Japan. ${ }^{6}$ College of Materials Science and Engineering, Nanjing Forestry University, Nanjing 210037, China.

\section{Acknowledgements}

The study was conducted within the framework of RISH Cooperative Research (ADAM), and RISH Mission Research II. The transverse sections investigated in this study were prepared by Dr. Miho Kojima and Prof. Keiji Takabe, Kyoto University, which are sincerely acknowledged. We thank Edanz Group (http:// www.edanzediting.com/ac) for editing a draft of this manuscript.

\section{Competing interests}

The authors declare that they have no competing interests. 


\section{Availability of data and materials}

The datasets generated during and/or analyzed during the current study are available from the corresponding author on reasonable request.

\section{Funding}

Sample preparation and fluorescence microscopy were supported by the New Energy and Industrial Technology Development Organization (NEDO) project entitled: "Construction of Innovative Saccharifying Enzyme-producing Microorganism and Development of Manufacturing of the Enzyme for the Biofuel Commercialization". Computational analysis was supported by Grant-in-Aid for Scientific Research (Grant Numbers 25252033, 18H05485).

\section{Publisher's Note}

Springer Nature remains neutral with regard to jurisdictional claims in published maps and institutional affiliations.

Received: 5 December 2018 Accepted: 20 March 2019 Published online: 27 March 2019

\section{References}

1. Horikawa Y, Konakahara N, Imai T, Abe K, Kobayashi Y, Sugiyama J (2013) The structural changes in crystalline cellulose and effects on enzymatic digestibility. Polym Degrad Stab 98:2351-2356. https://doi.org/10.1016/j. polymdegradstab.2013.08.004

2. Lou H, Wang M, Lai H, Lin X, Zhou M, Yang D, Qiu X (2013) Reducing nonproductive adsorption of cellulase and enhancing enzymatic hydrolysis of lignocelluloses by noncovalent modification of lignin with lignosulfonate. Bioresour Technol 146:478-484. https://doi.org/10.1016/j.biort ech.2013.07.115

3. Palonen H, Tjerneld F, Zacchi G, Tenkanen M (2004) Adsorption of Trichoderma reesei $\mathrm{CBH}$ I and EG II and their catalytic domains on steam pretreated softwood and isolated lignin. J Biotechnol 107:65-72. https:// doi.org/10.1016/j.jbiotec.2003.09.011

4. Gunjikar TP, Sawant SB, Joshi JB (2001) Shear deactivation of cellulase, exoglucanase, endoglucanase, and beta-glucosidase in a mechanically agitated reactor. Biotechnol Prog 17:1166-1168. https://doi.org/10.1021/ bp010114u

5. Atreya ME, Strobel KL, Clark DS (2016) Alleviating product inhibition in cellulase enzyme Cel7A. Biotechnol Bioeng 113:330-338. https://doi. org/10.1002/bit.25809

6. Cherry JR, Fidantsef AL (2003) Directed evolution of industrial enzymes: an update. Curr Opin Biotechnol 14:438-443

7. Liu G, Zhang J, Bao J (2016) Cost evaluation of cellulase enzyme for industrial-scale cellulosic ethanol production based on rigorous Aspen Plus modeling. Bioprocess Biosyst Eng 39:133-140. https://doi.org/10.1007/ s00449-015-1497-1

8. Beldman G, Voragen AG, Rombouts FM, Pilnik W (1988) Synergism in cellulose hydrolysis by endoglucanases and exoglucanases purified from Trichoderma viride. Biotechnol Bioeng 31:173-178. https://doi. org/10.1002/bit.260310211

9. Henrissat B, Driguez H, Viet C, Schülein M (1985) Synergism of cellulases from trichoderma reesei in the degradation of cellulose. Nat Biotechnol 3:722-726. https://doi.org/10.1038/nbt0885-722

10. Wood TM, McCrae SI, Bhat KM (1989) The mechanism of fungal cellulase action. Synergism between enzyme components of Penicillium pinophilum cellulase in solubilizing hydrogen bond-ordered cellulose. Biochem J 260:37-43

11. Chanzy H, Henrissat B, Vuong R (1984) Colloidal gold labelling of I,4- $\beta$ D-glucan cellobiohydrolase adsorbed on cellulose substrates. FEBS Lett 172:193-197. https://doi.org/10.1016/0014-5793(84)81124-2

12. White AR, Brown RM (1981) Enzymatic hydrolysis of cellulose: visual characterization of the process. Proc Natl Acad Sci USA 78:1047-1051

13. Jervis EJ, Haynes CA, Kilburn DG (1997) Surface diffusion of cellulases and their isolated binding domains on cellulose. J Biol Chem 272:2401624023. https://doi.org/10.1074/jbc.272.38.24016

14. Pinto R, Carvalho J, Mota M, Gama M (2006) Large-scale production of cellulose-binding domains. Adsorption studies using CBD-FITC conjugates. Cellulose 13:557-569. https://doi.org/10.1007/s1057 0-006-9060-5

15. Liu Y-S, Luo Y, Baker JO, Zeng Y, Himmel ME, Smith S, Ding S-Y (2010) A single molecule study of cellulase hydrolysis of crystalline cellulose. In: Single Molecule Spectroscopy and Imaging III. International Society for Optics and Photonics, p 757103

16. Wang L, Wang Y, Ragauskas AJ (2012) Determination of cellulase colocalization on cellulose fiber with quantitative FRET measured by acceptor photobleaching and spectrally unmixing fluorescence microscopy. Analyst 137:1319-1324. https://doi.org/10.1039/c2an15938d

17. Igarashi K, Koivula A, Wada M, Kimura S, Penttilä M, Samejima M (2009) High speed atomic force microscopy visualizes processive movement of Trichoderma reesei cellobiohydrolase I on crystalline cellulose. J Biol Chem 284:36186-36190. https://doi.org/10.1074/jbc.M109.034611

18. Igarashi K, Uchihashi T, Koivula A, Wada M, Kimura S, Okamoto T, Penttilä M, Ando T, Samejima M (2011) Traffic jams reduce hydrolytic efficiency of cellulase on cellulose surface. Science 333:1279-1282. https://doi. org/10.1126/science.1208386

19. Kawamori M, Ado Y, Takasawa S (1986) Preparation and application of Trichoderma reesei mutants with enhanced $\beta$-glucosidase. Agric Biol Chem 50:2477-2482. https://doi.org/10.1080/00021369.1986.10867787

20. Kawaguchi T, Enoki T, Tsurumaki S, Sumitani J, Ueda M, Ooi T, Arai M (1996) Cloning and sequencing of the cDNA encoding $\beta$-glucosidase 1 from Aspergillus aculeatus. Gene 173:287-288. https://doi. org/10.1016/0378-1119(96)00179-5

21. Kawai T, Nakazawa H, Ida N, Okada H, Tani S, Sumitani J, Kawaguchi T, Ogasawara W, Morikawa Y, Kobayashi Y (2012) Analysis of the saccharification capability of high-functional cellulase JN11 for various pretreated biomasses through a comparison with commercially available counterparts. J Ind Microbiol Biotechnol 39:1741-1749. https://doi.org/10.1007/ s10295-012-1195-9

22. Shibata N, Suetsugu M, Kakeshita $H$, Igarashi $K$, Hagihara $H$, Takimura $Y$ (2017) A novel GH10 xylanase from Penicillium sp. accelerates saccharification of alkaline-pretreated bagasse by an enzyme from recombinant Trichoderma reesei expressing Aspergillus $\beta$-glucosidase. Biotechnol Biofuels 10:278. https://doi.org/10.1186/s13068-017-0970-2

23. Tsuboi H, Koda A, Toda T, Minetoki T, Hirotsune M, Machida M (2005) Improvement of the Aspergillus oryzae enolase promoter (P-enoA) by the introduction of cis-element repeats. Biosci Biotechnol Biochem 69:206-208

24. Minetoki T, Kumagai C, Gomi K, Kitamoto K, Takahashi K (1998) Improvement of promoter activity by the introduction of multiple copies of the conserved region III sequence, involved in the efficient expression of Aspergillus oryzae amylase-encoding genes. Appl Microbiol Biotechnol 50:459-467

25. Thevenaz P, Ruttimann UE, Unser M (1998) A pyramid approach to subpixel registration based on intensity. IEEE Trans Image Process 7:27-41. https://doi.org/10.1109/83.650848

26. Pedregosa F, Varoquaux G, Gramfort A, Michel V, Thirion B, Grisel O, Blondel M, Prettenhofer P, Wiss R, Dubourg V, Vanderplas J, Passos A, Cournapeau D, Brucher M, Perrot M, Duchesnay É (2011) Scikit-learn: machine learning in Python. J Mach Learn Res 12:2825-2830

27. Xu J, Takakuwa N, Nogawa M, Okada H, Morikawa Y (1998) A third xylanase from Trichoderma reesei PC-3-7. Appl Microbiol Biotechnol 49:718-724. https://doi.org/10.1007/s002530051237

28. Matsuzawa T, Kaneko S, Yaoi K (2016) Improvement of thermostability and activity of Trichoderma reesei endo-xylanase Xyn III on insoluble substrates. Appl Microbiol Biotechnol 100:8043-8051. https://doi. org/10.1007/s00253-016-7563-z

29. Penttilä PA, Várnai A, Pere J, Tammelin T, Salmén L, Siika-aho M, Viikari $L$, Serimaa $R$ (2013) Xylan as limiting factor in enzymatic hydrolysis of nanocellulose. Bioresour Technol 129:135-141. https://doi.org/10.1016/j. biortech.2012.11.017

30. Fägerstam LG, Pettersson LG (1980) The 1.4- $\beta$-glucan cellobiohydrolases of Trichoderma reesei QM 9414: a new type of cellulolytic synergism. FEBS Lett 119:97-100. https://doi.org/10.1016/0014-5793(80)81006-4

31. Boisset C, Fraschini C, Schülein M, Henrissat B, Chanzy H (2000) Imaging the enzymatic digestion of bacterial cellulose ribbons reveals the endo character of the cellobiohydrolase Cel6A from Humicola insolens and its 
mode of synergy with cellobiohydrolase Cel7A. Appl Environ Microbiol 66:1444-1452

32. Rahkamo L, Siika-Aho M, Vehviläinen M, Dolk M, Viikari L, Nousiainen P, Buchert J (1996) Modification of hardwood dissolving pulp with purified Trichoderma reesei cellulases. Cellulose 3:153-163. https://doi. org/10.1007/BF02228798
33. Horikawa Y, Imai T, Abe K, Sakakibara K, Tsuji Y, Mihashi A, Kobayashi Y, Sugiyama J (2016) Assessment of endoglucanase activity by analyzing the degree of cellulose polymerization and high-throughput analysis by near-infrared spectroscopy. Cellulose 23:1565-1572. https://doi. org/10.1007/s10570-016-0927-9

\section{Submit your manuscript to a SpringerOpen ${ }^{\odot}$ journal and benefit from:}

- Convenient online submission

- Rigorous peer review

- Open access: articles freely available online

- High visibility within the field

- Retaining the copyright to your article

Submit your next manuscript at $\boldsymbol{\nabla}$ springeropen.com 